\title{
An experimental-computer modeling study
}

\section{of inorganic phosphates surface adsorption}

\section{on hydroxyapatite particles}

\section{Manuel Rivas, ${ }^{1, \bullet}$ Jordi Casanovas, ${ }^{2, \bullet}$ Luis J. del Valle, ${ }^{1, \bullet}$ Oscar}

Bertran, ${ }^{3, \triangleleft}$ Guillermo Revilla-López, ${ }^{1}$ Pau Turon,,${ }^{4, *}$ Jordi Puiggalí, ${ }^{1,5, *}$ and Carlos Alemán ${ }^{1,5, *}$

${ }^{1}$ Departament d'Enginyeria Química, E. T. S. d'Enginyeria Industrial de Barcelona, Universitat Politècnica de Catalunya, Diagonal 647, 08028 Barcelona, Spain

${ }^{2}$ Departament de Química, Escola Politècnica Superior, Universitat de Lleida, c/ Jaume II $n^{o}$ 69, Lleida E-25001, Spain

${ }^{3}$ Departament de Física Aplicada, EEI, Universitat Politècnica de Catalunya, Av. Pla de la Massa, 8, 08700 Igualada, Spain

${ }^{4}$ B. Braun Surgical, S.A. Carretera de Terrasa 121, 08191 Rubí (Barcelona), Spain

${ }^{5}$ Center for Research in Nano-Engineering, Universitat Politècnica de Catalunya, Campus Sud, Edifici C', C/Pasqual i Vila s/n, Barcelona E-08028, Spain

*Corresponding authors: pau.turon@bbraun.com, jordi.puiggali@upc.edu and carlos.aleman@upc.edu

-II These authors contributed equally to this work 


\begin{abstract}
The adsorption of orthophosphate, pyrophosphate, triphosphate and a trisphosphonate onto hydroxyapatite has been examined using experiments and quantum mechanical calculations. Adsorption studies with FTIR and X-ray photoelectron spectroscopies have been performed considering both crystalline hydroxyapatite (HAp) and amorphous calcium phosphate particles, which were specifically prepared and characterized for this purpose. Density Functional Theory (DFT) calculations have been carried out considering the (100) and (001) surfaces of HAp, which were represented using $1 \times 2 \times 2$ and $3 \times 3 \times 1$ slab models, respectively. The adsorption of phosphate onto such two crystallographic surfaces is very favored from an energetic point of view, which is fully consistent with current interpretations of HAp growing process. The structures calculated for the adsorption of pyrophosphate and triphosphate evidence that this process is easier for the latter than for the former. Thus, the adsorption of pyrophosphate is severely limited by the surface geometry while the flexibility of triphosphate allows transforming repulsive electrostatic interactions into molecular strain. On the other hand, calculations predict that the trisphosphonate only adsorps onto the (001) surface of HAp. Theoretical predictions are fully consistent with experimental data. Thus, comparison of DFT results and spectroscopic data suggest that the experimental conditions used to prepare HAp particles promote the predominance of the (100) surface. Accordingly, experimental identification of the adsorption of trisphosphonate onto such crystalline particles is unclear while the adsorption of pyrophosphate and triphosphate are clearly observed.
\end{abstract}




\section{INTRODUCTION}

Bone mineral crystals are compositionally and structurally similar to the synthetic hydroxyapatite (HAp), $\mathrm{Ca}_{10}\left(\mathrm{PO}_{4}\right)_{6}(\mathrm{OH})_{2}{ }^{1}$ Consequently, the ability of this bioceramic to interact with other with living systems, like cells, as well as with biomolecules are of key interest. In this work we focus on the capacity of HAp to interact with orthophosphate $\left(\mathrm{PO}_{4}^{3-}\right)$, pyrophosphate $\left(\mathrm{P}_{2} \mathrm{O}_{7}^{4-}\right)$ and polyphosphate (polyP). Furthermore, the study has been extended to biophosphonates (BPs), which are stable analogues of inorganic pyrophosphates. In order to illustrate the relevance of this topic for both biomedicinal and biotechnological fields, relationships between all these compounds and HAp are briefly discussed below.

In the last years scaffolds constructed with HAp have been used for bone regeneration. ${ }^{2-12} \mathrm{~A}$ very successful strategy was to enhance bone regeneration by adsorbing inorganic polyP onto HAp. ${ }^{13-18}$ PolyP, which is an orthophosphate polymer found in mammalian organisms, ${ }^{19}$ stabilizes basic cell growth and differentiation promoting bone regeneration. ${ }^{20-22}$ Furthermore, short chains of polyP have been detected, together with $\mathrm{P}_{2} \mathrm{O}_{7}^{4-}$, in human platelets, ${ }^{23}$ linking coagulation and inflammation. ${ }^{24}$ PolyP has also been identified in patients with myeloma cells, a malignant transformation of plasma cells. ${ }^{25}$ In addition, polyp plays an important role in cancer metastasis $^{26,27}$ and in virulence of different bacteria and a number of parasites. ${ }^{28}$

On the other hand, early studies reported that polyP and $\mathrm{P}_{2} \mathrm{O}_{7}^{4-}$ behave as $\mathrm{HAp}$ crystal growth inhibitors. ${ }^{29-31}$ More recently, Grynpas and coworkers ${ }^{32}$ proposed that the production of polyP, which forms strong complexes with divalent cations such as $\mathrm{Ca}^{2+},{ }^{33}$ can lead to a high local accumulations of total phosphate and $\mathrm{Ca}^{2+}$. Accordingly, polyP was proposed to play an important role in cartilage mineralization and bone 
formation, this hypothesis being supported by both the adsorption of polyP onto HAp and the correlation between the hydrolytic degradation of polyP in $\mathrm{Ca}^{2+}$-polyP complexes and the increment of $\mathrm{PO}_{4}^{3-}$ and $\mathrm{Ca}^{2+}$ concentrations.

Despite fifteen years ago Okazaki et $a l .{ }^{34}$ proposed that DNA inhibits HAp growth, more recent studies proved that the formation of HAp can be regulated by DNA, which acts as a template in the process of "biomineralization". ${ }^{35-38}$ Thus, the role of DNA as template to promote mineral formation and the own biomineralization mechanism has been recently examined at the atomic level. ${ }^{35-38}$ Results showed that calcium phosphate clusters are formed surrounding the polyP backbone of DNA, which acts as a very large nucleus for the growing of the HAp. Also, HAp nanoparticles are suitable as gene delivery systems for the transfection of cells with nucleic acids. ${ }^{39-41}$ Thus, HAp confers protection to DNA from chemical and enzymatic degradation, increasing the stability of the biomolecule. ${ }^{41,42}$

On the other hand, the BPs the oxygen atom that links the phosphate groups of pyrophosphates is replaced by a carbon atom. This substitution provokes resistance towards both hydrolytic and enzymatic degradations. ${ }^{43}$ It has been observed that the affinity of BPs towards HAp can be modulated by varying the chemical nature of the groups attached to the tertiary carbon atom. In particular, the incorporation of amino functionalities increases the affinity towards HAp. ${ }^{44-46}$ Recent studies suggested that nitrogen-containing BPs form strong hydrogen bonds with the HAp matrix. ${ }^{47}$ Furthermore, BPs are primary agents in the current pharmacological arsenal against different bone diseases (e.g. osteoporosis, Paget disease of bone and malignancies metastatic to bone). ${ }^{48}$ 
In this work we examine the adsorption of $\mathrm{PO}_{4}^{3-}, \mathrm{P}_{2} \mathrm{O}_{7}^{4-}$, polyP and aminotris(methylenephosphonic acid), a BP hereafter denoted ATMP, on HAp using a combined experimental-theoretical approach. In order to provide a clearer picture about the influence of the phosphate size on the whole adsorption process, sodium triphosphate $\left(\mathrm{Na}_{5} \mathrm{P}_{3} \mathrm{O}_{10}\right)$ has been used to describe polyP in both experiments and theoretical calculations. Initially, the adsorption of $\mathrm{P}_{2} \mathrm{O}_{7}^{4-}$ and polyP on both amorphous calcium phosphate and crystalline synthetic HAp (hereafter named ACP and cHAp, respectively) has been investigated using FTIR spectroscopy and X-ray photoelectron spectroscopy (XPS). Once this has been proved and the influence of the compound concentration and the $\mathrm{pH}$ have been determined, valuable microscopic information about the adsorption of $\mathrm{PO}_{4}^{3-}, \mathrm{P}_{2} \mathrm{O}_{7}^{4-}$, polyP and ATMP on HAp have been obtained using Density Functional Theory (DFT) calculations.

\section{METHODS}

Materials. Tetrasodium pyrophosphate $\left(\mathrm{P}_{2} \mathrm{O}_{7}^{4-}\right)$, sodium triphosphate (polyP), ATMP, ammonium phosphate dibasic $\left[\left(\mathrm{NH}_{4}\right)_{2} \mathrm{HPO}_{4}\right.$; purity $\left.\geq 99.0 \%\right]$ and ammonium hydroxide solution $30 \%\left(\mathrm{NH}_{4} \mathrm{OH}\right.$; purity: 28-30\%) were purchased from SigmaAldrich. Calcium nitrate $\left[\mathrm{Ca}\left(\mathrm{NO}_{3}\right)_{2}\right.$; purity $\left.\geq 99.0 \%\right]$ was purchased from Panreac (Barcelona, Spain). Ethanol $\left(\mathrm{C}_{2} \mathrm{H}_{5} \mathrm{OH}\right.$; purity $\left.\geq 99.5 \%\right)$ was obtained from Scharlab (Barcelona, Spain).

Synthesis of HAp. ACP and cHAp samples were prepared using the same procedure but applying different experimental conditions to the reaction mixture. Reagent conditions were adjusted to get a $\mathrm{Ca} / \mathrm{P}$ ratio of 1.67 . In all cases $15 \mathrm{~mL}$ of $0.5 \mathrm{M}$ 
$\left(\mathrm{NH}_{4}\right)_{2} \mathrm{HPO}_{4}$ in de-ionized water ( $\mathrm{pH}$ adjusted to 11 with ammonia $30 \%$ w/w) were added drop-wise $\left(2 \mathrm{~mL} \cdot \mathrm{min}^{-1}\right)$ and under agitation $(400 \mathrm{rpm})$ to $25 \mathrm{~mL}$ of $0.5 \mathrm{M}$ $\mathrm{Ca}\left(\mathrm{NO}_{3}\right)_{2}$ in ethanol. After that, the reaction mixture was stirred $1 \mathrm{~h}(400 \mathrm{rpm})$ at room temperature. In the case of ACP the resultant suspension was aged for $24 \mathrm{~h}$ at $37{ }^{\circ} \mathrm{C}$, whereas hydrothermal conditions were applied during $24 \mathrm{~h}$ for cHAp. In both cases, the precipitate was separated by centrifugation and sequentially washed with de-ionized water and a $60 / 40 \mathrm{v} / \mathrm{v}$ mixture of ethanol-water (twice). A white powder was obtained after freeze-drying.

X-Ray diffraction. Crystallinity was studied by wide angle X-ray diffraction (WAXD). Patterns were acquired using a Bruker D8 Advance model with $\mathrm{Cu} \mathrm{K}_{\alpha}$ radiation $(\lambda=0.1542 \mathrm{~nm})$ and geometry of Bragg-Bretano, theta- 2 theta. A onedimensional Lynx Eye detector was employed. Samples were run at $40 \mathrm{kV}$ and $40 \mathrm{~mA}$, with a 2-theta range of 10-60, measurement steps of $0.02^{\circ}$, and time/step of $2-8 \mathrm{~s}$. Diffraction profiles were processed using PeakFit v4 software (Jandel Scientific Software) and the graphical representation performed with OriginPro v8 software (OriginLab Corporation, USA).

The crystallite size $(L)$ in the direction representative to the (211) planes of samples was derived from the X-ray diffraction line broadening measurement using the Scherrer equation: ${ }^{49}$

$$
L=\frac{0.9 \lambda}{\beta \cos \theta}
$$

where $\lambda$ is the wavelength $\left(\mathrm{CuK}_{\alpha}\right), \beta$ is the full width at half maximum height of the (211) line, $\theta$ is the diffraction angle and 0.9 is a shape factor.

The crystallinity $\left(\chi_{c}\right)$ was obtained using the following Eqn: ${ }^{50}$ 


$$
\chi_{c}=1-\frac{\mathrm{V}_{112 / 300}}{\mathrm{I}_{300}}
$$

where $I_{300}$ is the intensity of the (300) reflection and $V_{112 / 300}$ is the intensity of the hollow between the (112) and (300) reflections, which disappears in non-crystalline samples.

Morphological characterization. Scanning electron microscopy (SEM) studies were carried out using a Focused Ion Beam Zeiss Neon40 microscope operating at $5 \mathrm{kV}$, equipped with an energy dispersive X-ray (EDX) spectroscopy system. Samples were deposited on a silicon disc mounted with silver paint on pin stubs of aluminum, and sputter-coated with a thin layer of carbon to prevent sample charging problems.

HAp protonation assay. The protonation ability of ACP and cHAp samples was determined using the following procedure: HAp particles suspended in milli-Q water (1 $\mathrm{mg} / \mathrm{mL}$ ) were protonated by adding an aqueous solution of $100 \mathrm{mM} \mathrm{HCl}$ and $50 \mathrm{mM}$ $\mathrm{NaCl}$ up to $\mathrm{pH} \approx 3$. Samples $(5 \mathrm{~mL})$ were maintained in a vial with continuous stirring, the $\mathrm{pH}$ values being determined every minute at $20^{\circ} \mathrm{C}$ using a $\mathrm{pH}$-meter. The total time for this assay was 15 minutes.

Adsorption onto ACP and cHAP. The ability of ACP and cHAp to adsorb polyP, $\mathrm{P}_{2} \mathrm{O}_{7}^{4-}$ and ATMP was determined using FTIR spectroscopy. The effects of both the concentration of adsorbate and the $\mathrm{pH}$ in the adsorption process were examined by preparing different working aqueous solutions, which were subsequently used for the incubation process. More specifically, the concentration of the adsorbate in the working solutions ranged from 25 to $200 \mathrm{mM}$ while the pHs considered in this study were $4,6,7$ and 9. In the case of $\mathrm{P}_{2} \mathrm{O}_{7}^{4-}$ such concentrations were reduced to a half (i.e. from 12.5 to $100 \mathrm{mM}$ ) because of limitations in the solubility of this specie. 
For the incubation, $500 \mu \mathrm{L}$ of the working solution with the adsorbate were deposited onto $50 \mathrm{mg}$ of ACP or cHAp. After overnight agitation at $25^{\circ} \mathrm{C}$, adducts were separated by centrifugation at $6500 \mathrm{rpm}$ during 5 minutes at $4{ }^{\circ} \mathrm{C}$. Sediments were resuspended in distilled water. After this process, which was repeated two times, the obtained pellets were frozen at $-80{ }^{\circ} \mathrm{C}$ for $3 \mathrm{~h}$ and, subsequently, the humidity was removed using a lyophilizer.

Fourier transform infrared (FTIR) spectroscopy. Infrared absorption spectra were recorded with a Fourier Transform FTIR 4100 Jasco spectrometer in the 1800-700 cm-1 range. A Specac model MKII Golden Gate attenuated total reflection (ATR) equipment with a heated Diamond ATR Top-Plate was used. The characteristic bands of the compounds studied in this work (substrates and adsorbed species) are listed in Table 1.

$X$-ray photoelectron spectroscopy (XPS). XPS analyses were performed in a SPECS system equipped with a high-intensity twin-anode X-ray source XR50 of Mg/Al (1253 $\mathrm{eV} / 1487 \mathrm{eV}$ ) operating at $150 \mathrm{~W}$, placed perpendicular to the analyzer axis, and using a Phoibos 150 MCD-9 XP detector. The X-ray spot size was $650 \mu \mathrm{m}$. The pass energy was set to 25 and $0.1 \mathrm{eV}$ for the survey and the narrow scans, respectively. Charge compensation was achieved with a combination of electron and argon ion flood guns. The energy and emission current of the electrons were $4 \mathrm{eV}$ and $0.35 \mathrm{~mA}$, respectively. For the argon gun, the energy and the emission current were $0 \mathrm{eV}$ and $0.1 \mathrm{~mA}$, respectively. The spectra were recorded with a pass energy of $25 \mathrm{eV}$ in $0.1 \mathrm{eV}$ steps at a pressure below $6 \times 10^{-9}$ mbar. These standard conditions of charge compensation resulted in a negative but perfectly uniform static charge. The $\mathrm{C} 1 \mathrm{~s}$ peak was used as an internal reference with a binding energy of $284.8 \mathrm{eV}$. High-resolution XPS spectra were acquired by Gaussian-Lorentzian curve fitting after s-shape background subtraction. The surface composition was determined using the manufacturer's sensitivity factors. 
Quantum mechanical calculations. All DFT calculations were performed using the Gaussian $09^{51}$ computer package. Both the (100) and (001) surfaces of HAp, which were represented without periodic boundary conditions but using relatively large slab models, were considered for all the examined adsorbates. More specifically, the following strategy was used to choose the dimensions of the slab models. Initially the orthophosphate adsorption onto HAp was studied considering following slab dimensions for the $(100)$ surface: $1 \times 1 \times 1,1 \times 1 \times 2,2 \times 1 \times 2$ and $1 \times 2 \times 2$; while for the $(001)$ surface these were: $2 \times 1 \times 1,2 \times 2 \times 1,2 \times 2 \times 2$ and $3 \times 3 \times 1$. The selection of the models was based on the following two conditions: (i) the interaction pattern between the surface and the adsorbate is not altered by the enlargement of the slab dimensions (i.e. the influence of the boundary effects in the mode of interaction is null); and (ii) the variation of the binding energy (BE) due to the enlargement of the slab model is $\leq 8 \%$. In this work, only results obtained using the two larger slab models, which were used to adsorb $\mathrm{P}_{2} \mathrm{O}_{7}^{4-}$, polyP and ATMP, are discussed since interactions provided the smaller models are not representative. Table 2 displays the molecular formulas of all systems studied in this work (both adsorbed molecules and slab models).

The hexagonal HAp crystal unit cell with $P 6_{3} / m$ geometry $(a=b=9.421 \AA$, $c=6.881$ $\AA, \alpha=\beta=90^{\circ}$, and $\gamma=120^{\circ}$ ) and the $4 \mathrm{e}$ Wyckoff position occupied by two hydroxyl ions, each with $1 / 2$ occupancy, ${ }^{52}$ was generated and, subsequently, was cleaved to obtain the (100) and (001) surfaces. Initial configurations for the adsorptions complexes between the two considered surfaces and the four studied compounds $\left(\mathrm{PO}_{4}^{3-}, \mathrm{P}_{2} \mathrm{O}_{7}^{4-}\right.$, polyP and ATMP) were prepared by considering all possible coordination modes. Geometries of the different initial adsorbate configurations for all the investigated 
systems were fully optimized using the B3LYP ${ }^{53,54}$ functional combined with the 6$31 \mathrm{G}(\mathrm{d})$ basis set.

BEs were corrected with the basis set superposition error (BSSE) by mean of the standard counterpoise $(\mathrm{CP})$. The $\mathrm{BE}$ of the complex is defined as usual by subtracting the energy of the surface and the adsorbate from the energy of the complex. It should be remarked that, due to the limitations of models described above (i.e. gas-phase, limited size of the surface, static description of the system, etc...), the calculated BEs cannot be interpreted as a quantitative description of the strength of the system. However, qualitative comparison of the relative BEs is expected to provide microscopic understanding of experimental observations.

\section{RESULTS AND DISCUSSION}

Characterization of ACP and cHAp. The morphologies of ACP and cHAp, which are displayed in Figure S1, reflect the noticeable influence of hydrothermal and aging conditions. cHAp samples, which were prepared using hydrothermal conditions, show laminar crystals and fusiform rods, while ACP particles obtained using open aging, exhibit an pseudo-spherical morphology of nanometric dimensions. The average dimensions of ACP pseudo-spheres and cHAp rods are displayed in Table 3.

Characterization of two synthesized particles by X-ray diffraction (Figure S2) was focused on peaks at $2 \theta$ between $31.5^{\circ}$ and $34.5^{\circ}$, which correspond to the (211), (112), and (300) HAp reflections. The crystallinity and crystallite size determined for ACP and cHAp samples are listed in Table 3. The physical differences between ACP and cHAp particles are expected to affect their properties. This is proved in Figure S3, which compares the response of the two HAp particles to acidic environments. Thus, titration 
results display a steep $\mathrm{pH}$ gradient for $\mathrm{cHAp}$, whereas the slow and gradual variation of the $\mathrm{pH}$ evidences a remarkable buffering effect for the ACP sample. This result indicates that crystallinity plays a major role reducing the proton-buffering capacity of HAp.

Experimental detection of adsorption onto ACP and cHAp. The FTIR spectra of the synthesized ACP and cHAP, polyP, $\mathrm{P}_{2} \mathrm{O}_{7}^{4-}$ and ATMP are displayed in Figure S4, while the most characteristic bands of each compound are listed in Table 1 . It should be noted that the asymmetric and symmetric stretching vibration of the $\mathrm{P}-\mathrm{O}-\mathrm{P}$ bridges are characteristic of polyP and $\mathrm{P}_{2} \mathrm{O}_{7}^{4-}$, even though they are not observed for ACP and cHAp. The $\mathrm{PO}_{3}^{2-}$ vibration modes of polyP and $\mathrm{P}_{2} \mathrm{O}_{7}^{4-}$ are detected in $1000-1200 \mathrm{~cm}^{-1}$ domain, as detailed in previous work. ${ }^{55}$ On the other hand, the ATMP spectrum was recently described by some of us. ${ }^{56}$

Figure 1 displays the FTIR spectra of cHAp and ACP recorded after incubation in solutions with different concentrations of polyP, $\mathrm{P}_{2} \mathrm{O}_{7}^{4-}$ and ATMP at neutral $\mathrm{pH}$. For polyP the characteristic absorption band is clearly identified at around $891-894 \mathrm{~cm}^{-1}$ for all concentrations $\geq 50 \mathrm{mM}$, even though it is only a weak shoulder for $25 \mathrm{mM}$. The band at $734 \mathrm{~cm}^{-1}$ is only detectable for the largest concentration, $200 \mathrm{mM}$. Regarding the adsorption of $\mathrm{P}_{2} \mathrm{O}_{7}^{4-}$, a very weak shoulder associated to the band at $889 \mathrm{~cm}^{-1}$ is observed for all tested concentrations while, in opposition, the band at $736 \mathrm{~cm}^{-1}$ remains practically undetectable. Although these results evidence the adsorption of polyP and $\mathrm{P}_{2} \mathrm{O}_{7}^{4-}$, difficulties in the identification of some characteristic bands suggest some limitations in such association processes. Theoretical calculations provide microscopic 
details about such limitations in next sub-sections. Unfortunately, identification of adsorbed ATMP molecules is a very complex task, especially in cHAp samples, in which no clear band is observed. For ACP, the shoulder detected at $\sim 900 \mathrm{~cm}^{-1}$ for ATMP concentrations $\leq 100 \mathrm{mM}$, transforms into a broad but weak band for $200 \mathrm{mM}$.

The influence of the $\mathrm{pH}$ in the adsorption process is displayed in Figure 2, which shows the FTIR spectra of cHAp and ACP after incubation in $200 \mathrm{mM}$ polyP, $100 \mathrm{mM}$ $\mathrm{P}_{2} \mathrm{O}_{7}^{4-}$ and $200 \mathrm{mM}$ ATMP at $\mathrm{pH}$ 6, 7 and 9. As it can be seen, adsorption is detected in all cases, even though changes in the spectra recorded at $\mathrm{pH} 6$ point to the degradation of the nanoparticles. This is particularly evident for ACP, which presents the higher proton-buffering capacity than cHAp. Such feature suggests that the chemical protection against the acid is provoked by the delivery of anionic species during the degradation process. On the other hand, the adsorption of polyP and $\mathrm{P}_{2} \mathrm{O}_{7}^{4-}$ is apparently favored at pH 7 with respect to $\mathrm{pH} 9$ for both $\mathrm{ACP}$ and $\mathrm{cHAP}$, this feature being corroborated by the ratios (not shown) between the intensity of the characteristic band associated to each of these compound and the intensity of the $\mathrm{PO}_{4}^{3-}$ band for cHAP and ACP.

The ability of cHAp and ACP to bind polyP and $\mathrm{P}_{2} \mathrm{O}_{7}^{4-}$ has been corroborated by XPS. Figure S5 represents the characteristic XPS spectra in the O1s region of cHAp as prepared and after incubation in presence of polyP $(200 \mathrm{mM}), \mathrm{P}_{2} \mathrm{O}_{7}^{4-}(100 \mathrm{mM})$ and ATMP (200 mM). The sharp peak at $531.2 \mathrm{eV}$ involve in all cases to the O1s of the $\mathrm{PO}_{4}^{3-}$ and $\mathrm{OH}^{-}$groups of cHAP. ${ }^{57}$ The spectra of samples incubated in presence of polyP and $\mathrm{P}_{2} \mathrm{O}_{7}^{4-}$ show a shoulder at $533.3 \mathrm{eV}$, which corresponds to the oxygen atom involved in symmetric bridging $\mathrm{P}-\mathrm{O}-\mathrm{P}$ groups of the adsorbed molecules. ${ }^{58}$ This result supports the adsorption previously detected by FTIR spectroscopy. Finally, the broad 
peak at $536.3 \mathrm{eV}$, which is only detected in samples with adsorbed polyP and $\mathrm{P}_{2} \mathrm{O}_{7}^{4-}$, can be attributed to non-bridging oxygen atoms, ${ }^{59}$ water accompanying the adsorbed compounds $^{60}$ or a combination of both.

Theoretical characterization of orthophosphate adsorption onto HAp. The two HAp planes considered in this work are the (001) and (100), which is isostructural with the (010). The (001) is the most stable HAp surface ${ }^{61-64}$ and was identified as the crystal growth plane during the biomineralization of teeth and hard tissues. ${ }^{64-66}$ Figure $3 \mathrm{a}$ shows the projection of the (001) plane in the unit cell as well as the $2 \times 2 \times 1$ and $3 \times 3 \times 1$ slab models. In order to preserve as much as possible the surface symmetry and the electroneutrality, species farthest from the center of the supercell were added in the first model, or removed in the second one. As a consequence of such changes, the boundaries of the two surfaces present some differences that involve the hydroxyl groups. However, comparison between the results obtained for these slab models (see below) indicated that such differences are located far enough from the adsorption sites and do not affect the interaction pattern. The selected $2 \times 2 \times 1$ and $3 \times 3 \times 1$ models contain 201 and 293 explicit atoms, respectively. On the other hand, it is not possible to construct a slap of the (100) surface with same termination at both sides. Thus, construction of a stable (100) surface, in which the total dipole moment across the slab perpendicular to the surface is zero, leads to sides that differ in the content of $\mathrm{OH}^{-}$and $\mathrm{Ca}^{2+}$ ions. One side only contains $\mathrm{Ca}^{2+}$ and $\mathrm{PO}_{4}^{3-}$ while the other side involves $\mathrm{Ca}^{2+}$, $\mathrm{OH}^{-}$and $\mathrm{PO}_{4}^{3-}$. In a recent study ${ }^{41}$ we found that the binding of DNA is disfavored for the latter termination. In this study we have only considered the termination with $\mathrm{OH}^{-}$ 
and $\mathrm{Ca}^{2+}$ ions for the (100) surface. Figure $3 \mathrm{~b}$ represents the projection of the (100) plane in the unit cell as well as the $1 \times 2 \times 2$ slab model (176 explicit atoms).

Although different initial configurations were considered for the adsorption of $\mathrm{PO}_{4}^{3-}$ onto the (001) and (100) surfaces of HAp, all them converged to the same complex (i.e. excluding those complexes in which the adsorbate moved towards the outer regions of the finite model used to described the surface) and those in which the slab model was too small (i.e. $2 \times 1 \times 1$ and $1 \times 1 \times 1$ for the $(001)$ and (100), respectively). Figure 4 displays details of the geometric features of the adsorbed complex obtained for each surface while binding energies (BEs) are displayed in Table 4. As it can be seen in Figure 4a, which represents the complex calculated using the largest slab model, the adsorption of $\mathrm{PO}_{4}^{3-}$ involves two interaction sites located at different heights. Consequently, the resulting $\mathrm{Ca}^{2+} \ldots \mathrm{O}$ distances differ by $\sim 0.15 \AA$ in the two calculated models. Although the BE improves by increasing the slab size of the (001) surface, the adsorption onto the (100) surface is clearly favored. The adsorption onto the (100) surface occurs through a tridentate coordination mode (Figure $4 \mathrm{~b}$ ). The additional interaction site and the most favorable geometry, which is reflected by smaller $\mathrm{Ca}^{2+} \ldots \mathrm{O}$ distances, provoke a reduction in the $\mathrm{BE}$ with respect to that obtained the (001) surface. On the other hand, it should be mentioned that enlargement of the thickness of the simulated HAp using the slab models described in Table 2 does not provide any change in terms of both interaction pattern and relative BEs for both (100) and (001) surfaces (Table 4).

The favorable BEs obtained for adsorption of $\mathrm{PO}_{4}^{3-}$ onto the examined surfaces (Table 4) is consistent with the different models used to explain the crystal growth of HAp. In the current interpretation of the crystal growth process, the existence of calcium phosphate clusters acting as HAp growth unit seems to be widely accepted. ${ }^{67,68}$ 
Following such cluster growth model, the formation of small calcium phosphate particles has been also examined using computer simulation techniques based on classical force-fields, which evidenced that clusters play a key role in the biomineralization process. ${ }^{38,69}$ Another model is the surface-induced crystallization, which is a common event in the mineralization of bone and dental hard tissues. The low interfacial energy between $\mathrm{PO}_{4}^{3-}$ and the HAp surfaces ${ }^{67,70}$ clearly suggests that adsorption of the former ions favors the crystal growth from an early forming phase. Quantum mechanical results described in this section evidence that the incorporation of new $\mathrm{PO}_{4}^{3-}$ ions onto both already formed crystals and incipient crystals formed through the aggregation of small clusters is very favored from an energetic point of view.

\section{Theoretical characterization of pyrophosphate adsorption onto HAp. Different}

possible orientations of the $\mathrm{P}_{2} \mathrm{O}_{7}^{4-}$ anion onto the (100) surface of HAp were identified, all such configurations being constructed and used as starting geometries for calculations. Geometry optimizations using the $1 \times 2 \times 2$ slab model led to different minima with favorable BEs. Figure 5a displays the disposition of the $\mathrm{P}_{2} \mathrm{O}_{7}^{4-}$ molecule onto the (100) surface for the most stable complex, the BE being included in Table 4. The adsorption occurs through four monodentate sites, which provides a symmetric interaction pattern with two asymmetric bindings at each phosphate unit. Thus, the two $\mathrm{Ca}^{2+} \ldots \mathrm{O}-\mathrm{P}$ distances associated to each phosphate unit are $\sim 2.27$ and $2.42 \AA$. Local minima with similar $\mathrm{BEs}$ and $\mathrm{Ca}^{2+} \ldots \mathrm{O}-\mathrm{P}$ distances were also obtained, a representative one being shown in Figure $5 \mathrm{~b}$. In this structure, which is $42 \mathrm{kcal} / \mathrm{mol}$ less stable than the global minimum, the interaction also occurs through four monodentate sites. 
Calculations related to the adsorption of $\mathrm{P}_{2} \mathrm{O}_{7}^{4-}$ onto the (001) surface did not lead to any stable complex. Thus, the most frequent situation, which was identified from different starting configurations, corresponded to the fragmentation of the $\mathrm{P}_{2} \mathrm{O}_{7}^{4-}$ molecule into $\mathrm{PO}_{4}^{3-}$ and $\mathrm{PO}_{3}^{-}$. Then, the $\mathrm{PO}_{4}^{3-}$ anion was adsorbed onto the surface in a coordination mode similar to that displayed in Figure $3 \mathrm{a}$ while the $\mathrm{PO}_{3}^{-}$fragment, which is less stable, was repelled by the surface.

The overall of these results is fully consistent with experimental observations displayed in Figure 1. Thus, the very weak shoulder detected at $889 \mathrm{~cm}^{-1}$ indicates that the adsorption of $\mathrm{P}_{2} \mathrm{O}_{7}^{4-}$ onto the mineral is a restricted to surfaces in which the positions of the $\mathrm{Ca}^{2+}$ cations favor the process energetically. Furthermore, the disposition of adsorption sites with respect to crystallographic positions of $\mathrm{Ca}^{2+}$ and $\mathrm{PO}_{4}^{3-}$ in HAp suggests agree with the role attributed to $\mathrm{P}_{2} \mathrm{O}_{7}^{4-}$ as HAp crystal growth inhibitor. $^{29-31}$ This is supported by the systematic formation of asymmetric links in all stable complexes, which are identified by different $\mathrm{Ca}^{2+} \ldots \mathrm{O}-\mathrm{P}$. Thus, adsorbed $\mathrm{P}_{2} \mathrm{O}_{7}^{4-}$ molecules should be viewed as important structural defects appeared onto the adsorption surface. Moreover, destruction of adsorbed $\mathrm{P}_{2} \mathrm{O}_{7}^{4-}$ molecules by the action of tissue non-specific alkaline phosphatase has been shown to favor the mineralization by promoting the continuation of previously inhibited crystal growth. ${ }^{71}$

Theoretical characterization of polyphosphate adsorption onto HAp. Six different configurations were constructed to study the adsorption of polyP onto each examined HAp surface. In the most stable structure obtained after optimization of the 
configurations constructed for the (100) surface (Figure 6), the three phosphate units of the polyP molecule participate in the coordination with the surface. Specifically, six oxygen atoms interact with four $\mathrm{Ca}^{2+}$ cations at the surface and the $\mathrm{Ca}^{2+} \ldots \mathrm{O}$ distances range from 2.372 to $2.498 \AA$. Comparison with the previously calculated complexes indicates that such interval of variation increases with the size of the adsorbate. Thus, the $\mathrm{Ca}^{2+} \ldots \mathrm{O}$ distances in complexes involving $\mathrm{P}_{2} \mathrm{O}_{7}^{4-}$ and $\mathrm{PO}_{4}^{3-}$ ranged from 2.270 to $2.418 \AA$ and from 2.307 to $2.327 \AA$, respectively. This is consistent with differences in the strength of the complexes. Analysis of the BEs obtained for the most stable complex of $\mathrm{PO}_{4}^{3-}, \mathrm{P}_{2} \mathrm{O}_{7}^{4-}$ and polyP adsorbed onto the $1 \times 2 \times 2$ slab model of the $(100)$ surface (Table 4) indicates that the strength of the interaction between the adsorbate and the surface increases less than expected with the number of $\mathrm{Ca}^{2+} \ldots \mathrm{O}$ interactions. Thus, the $\mathrm{BE}$ decreases $-153.9 \mathrm{kcal} / \mathrm{mol}$ when the number of interactions increases from 3 in $\mathrm{PO}_{4}^{3-}$ to 4 in $\mathrm{P}_{2} \mathrm{O}_{7}^{4-}$, such stabilization being of only $-122.7 \mathrm{kcal} / \mathrm{mol}$ when the number of interactions enlarges from 4 to 6 in polyP. Such behavior is due to the fact that the restrictions in the complexation process increase with the number of phosphate units in the adsorbate. In order to avoid repulsive interactions with the anions located at the surface, the adsorbate adapts its geometry to the crystallographic positions of the $\mathrm{Ca}^{2+}$ ions, provoking strain. This effect increases with the size of the adsorbate, explaining the enlargement of the $\mathrm{Ca}^{2+} \ldots \mathrm{O}$ distances and the reduction in the strength of the interaction.

Most of the structures constructed to study the adsorption of polyP onto the $3 \times 3 \times 1$ slab model of the (001) surface led to the decomposition of polyP into fragments (i.e. one fragment remained adsorbed onto the surface while the other was repelled, as observed above for the pyrophosphate). However, a stable complex, which is displayed 
in Figure 6a, was also achieved. In this structure two $\mathrm{Ca}^{2+}$ cations act as coordination sites, interacting with two and one oxygen atoms located at the two end phosphate units of the adsorbed polyP molecule. In contrast, the central phosphate unit of polyP does not interact with the surface. The most remarkable characteristic of this complex is the significant strain exhibited by the adsorbate. This is reflected by the values of the two $\angle \mathrm{P}-\mathrm{O}-\mathrm{P}$ angles, which are $174.1^{\circ}$ and $105.8^{\circ}$ in the complex and $144.2^{\circ}$ in the free-state (i.e. $\angle \mathrm{P}-\mathrm{O}-\mathrm{P}$ angles are $137.2^{\circ}$ and $140.4^{\circ}$ in the structure displayed in Figure $6 \mathrm{~b}$ ). In spite of this strain and poor coordination, the $\mathrm{Ca}^{2+} \ldots \mathrm{O}$ distances are relatively short in comparison to those obtained for the (100) surface (Figure 6b). The BE is similar to that obtained for the $\mathrm{P}_{2} \mathrm{O}_{7}^{4-}$ molecule adsorbed onto the (100) surface, which showed four $\mathrm{Ca}^{2+} \ldots \mathrm{O}$ interactions.

The overall of these results indicate that adsorption of polyP onto HAp is easier than of $\mathrm{P}_{2} \mathrm{O}_{7}^{4-}$. The $\mathrm{BE}$ decreases with the increasing number of phosphate units when the $\mathrm{Ca}^{2+}$ sites are located at favorable positions, as occurs in the (100) surface (Table 4). Furthermore, the additional phosphate unit of polyP facilitates the interaction with surfaces in which the position of the coordination sites is not adequate. Thus, although unfavorable repulsive electrostatic interactions induced by the (001) surface provokes strain in central phosphate unit of polyP, an energetically favorable adsorption process is achieved through the end phosphate units. In contrast, the repulsive electrostatic interactions exerted by the (001) surface provoked the fragmentation of $\mathrm{P}_{2} \mathrm{O}_{7}^{4-}$. These features are in excellent agreement with experimental observations displayed in Figures 1 and 2, which evidence that the adsorption of polyP onto cHAp is more clear than that of $\mathrm{P}_{2} \mathrm{O}_{7}^{4-}$ for all the tested concentrations. 
Theoretical characterization of ATMP adsorption onto HAp. Five different starting configurations of ATMP adsorbed onto the (100) surface were build. After geometry optimization, none of such complexes resulted stable and the adsorbate broke into two fragments. As occurred for $\mathrm{P}_{2} \mathrm{O}_{7}^{4-}$, a fragment remained onto the surface while repulsive interactions repelled the other.

Six starting geometries were constructed for the adsorption of ATMP onto the $3 \times 3 \times 1$ slab model of the (001) surface, the most stable structure derived from geometry optimization being displayed in Figure 7. In this tricoordinated structure ATMP makes one monodentate $\mathrm{O} \cdots \mathrm{Ca}^{2+}$ interaction and two bidentate interactions, in which two different oxygen atoms bind the same $\mathrm{Ca}^{2+}$. The $\mathrm{Ca}^{2+} \ldots \mathrm{O}$ distances range from 2.358 to $2.541 \AA$, evidencing that the adsorption of ATMP onto the (001) surface is due to the balance between the number and strength of the $\mathrm{Ca}^{2+} \cdots \mathrm{O}$ interactions. Furthermore, comparison of the geometries displayed in Figures $6 \mathrm{~b}$ and 7 , as well as of the BEs (Table 4) clearly indicates that the adsorption of ATMP onto the (001) surface is favored with respect to the adsorption of polyP on the same surface.

It is worth noting that the overall of theoretical results is fully consistent with the FTIR spectra displayed in Figure 1. Thus, calculations predict that complexes derived from the adsorption of polyP and $\mathrm{P}_{2} \mathrm{O}_{7}^{4-}$ onto the (100) surface of HAp are very stable from an energetic point of view, whereas the adsorptions of such species onto the (001) surface are energetically disfavored. In contrast, DFT calculations predict that ATMP only adsorbs onto the (001) surface (Figure 7). FTIR spectra clearly proved the adsorption of polyP and $\mathrm{P}_{2} \mathrm{O}_{7}^{4-}$ onto cHAp suggesting that such crystalline nanoparticles are dominated by the (100) surface. According to this, the adsorption of 
ATMP onto cHAp should not be a favored process and, consistently, no clear absorption band was identified for cHAp incubated in ATMP solutions. This excellent correlation between theoretical and experimental results provides direct understanding on the adsorption mechanism. Furthermore, it should be noted that previous studied evidenced that the dominant surface of crystalline nanoparticles depend on the experimental conditions used for their preparation. ${ }^{41}$ This feature suggests that the adsorption process can be modulated a priori during the synthesis of HAp.

Adsorption provokes the nucleation of crystals. As a proof of concept, the growing of polyP, $\mathrm{P}_{2} \mathrm{O}_{7}^{4-}$ and ATMP crystals onto the surface of cHAp and ACP particles was investigated. Thus, molecular adsorption is necessarily the initial stage of such surface-induced crystal growing process. Figure S6 shows high resolution SEM micrographs of cHAp and ACP samples after incubation in concentrated solutions of polyP $(2 \mathrm{M}), \mathrm{P}_{2} \mathrm{O}_{7}^{4-}(1 \mathrm{M})$ and ATMP $(2 \mathrm{M})$. As it can be seen, in all cases crystals grew onto the surface of both cHAp and ACP particles corroborating the molecular adsorción processes described in previous sub-sections.

\section{CONCLUSIONS}

The combination between experimental techniques and atomistic quantum mechanical calculations have been used to prove that the interaction betwwen $\mathrm{PO}_{4}^{3-}$, $\mathrm{P}_{2} \mathrm{O}_{7}^{4-}$, polyP or ATMP and HAp occurs in very different ways. While the adsorption of $\mathrm{PO}_{4}^{3-}$ onto $\mathrm{HAp}$ is a very favored process that promotes the crystal growth, the interaction of $\mathrm{P}_{2} \mathrm{O}_{7}^{4-}$ with the mineral depends on the geometry of the crystal surface, 
which can induce strong repulsive surface $\cdots$ adsorbate interactions. An intermediate situation is observed for polyP that, due to its higher number of phosphate units, remains adsorbed onto all tested surfaces. Thus, when the geometry of the surface is not appropriated, the adsorbed polyP molecule turns repulsive interactions into molecular strain while retain enough attractive adsorbate $\cdots$ surface interactions. The interactions described by theoretical calculations are fully consistent with experimental data, which clearly indicate that polyP adsorbs onto cHAp more easily than $\mathrm{P}_{2} \mathrm{O}_{7}^{4-}$. On the other hand, DFT calculations predict the molecular architecture of ATMP is not compatible with the geometry of the (100) surface while adsorption of such BP onto the (001) surface is energetically favored. This, result is fully consistent with the conclusions reached from the comparison of theoretical and experimental results achieved for mono, di- and triphosphates, which indicated that the behavior of the cHAp particles prepared in this work is dominated by the (100) surface.

In summary, our findings provide relevant information related not only with the abilities of crystalline HAp and ACP to interact with $\mathrm{PO}_{4}^{3-}, \mathrm{P}_{2} \mathrm{O}_{7}^{4-}$, polyP and ATMP but also with the chemical microscopic details that are responsible of the formation or not of such interactions. The interactions between the inorganic systems described in this work are relevant for the biomedical field. Phosphates play a crucial role in bone regeneration and have been identified in platelets and carcinogenic cells. The fact that phosphates have an important role in cancer metastasis and in the virulent effects of some bacteria and parasites, make these results interesting for the design of new treatments based on the adsorption ability of HAp. On the other hand, nitrogencontaining BPs are currently used in medical therapies related with bone degradation and malignancies, as for example osteoporosis and metastasis, respectively. Also results 
obtained in the work contribute to understanding of biomineralization, which should be considered relevant not only as new therapeutic approximation but also as a process related with the origin of life.

\section{ACKNOWLEDGEMENTS}

This work was supported by B. Braun Surgical S.A. through a joint research agreement with UPC, MINECO-FEDER funds (MAT2012-34498 and MAT201236205), and by the Generalitat de Catalunya (XRQTC). Special thanks to Mr. M. Jiménez for supporting the idea. This work is integrated within a wider research project supported by B. Braun Surgical S.A., UPC and other institutions. Authors are indebted to the Centre de Supercomputació de Catalunya (CESCA) for computational facilities.

\section{REFERENCES}

1. M. J. Glimcher, Metabolic Bone Disease and Clinically Related Disorders, Academic Press, New York, 1998, 23-50.

2. W. Bensaid, K. Oudina, V. Viateau, E. Potier, V. Bousson, C. Blanchat, L. Sedel, G. Guillemin and H. Petite, Tissue Eng., 2005, 11,814-824.

3. M. Mastrogiacomo, A. Corsi, E. Francioso, M. Di Comite, F. Monetti, S. Scaglione, A. Favia, A. Crovace, P. Bianco and R. Cancedda, Tissue Eng., 2006, $12,1261-1273$.

4. M. C. Kruyt, C. E. Wilson, J. D. de Bruijn, C. A. van Blitterswijk, C. F. Oner, A. J. Verbout and W. J. A. Dhert, Biomaterials, 2006, 29, 5099-5106.

5. M. Marcacci, K. Kon, V. Moukhachev, A. Lavroukov, S. Kutepov, R. Quarto and M. Mastrogiacomo and R. Cancedda, Tissue Eng., 2007, 13, 947-955. 
6. S. M. Zakaria, S. H. Sharif, M. R. Othman, F. Yang and J.A. Jansen, Tissue Eng. Part B Reviews , 2013, 19, 431-441.

7. D. A. Cardoso, J. A. Jansen and S. C. G. Leewenburgh, J. Biomed. Mater. Res. Part B Reviews, 2012, 100, 2316-2326.

8. J. M. Holzwart and P. X. Ma, Biomaterials, 2011, 32, 9622-9629.

9. F.-M. Chen, J. Zhang, M. Zhang, Y. An, F. Chen and Z.-F. Wu, Biomaterials, 2010, 31, 7892-7927.

10. T. Matsumoto, M. Okazaki, A. Nakahira, J. Sasaki, H. Egusa and T. Sohmura, Curr. Med. Chem., 2007, 14, 2726-2733.

11. R. Candedda, P. Giannoni, and M. Mastrogiacomo, Biomaterials, 2007, 28, 42404250.

12. S. V. Dorozhkin, Biomaterials, 2010, 31, 1465-1485.

13. K. Doi, T. Kubi, R. Takeshita, S. Kajihara, S. Kato, Y. Kawazoe, T. Shiba and Y. Akagawa, Dent. Mat. J., 2014, 33, 179-186.

14. P.A. Comeau, H. Frei, C.Yang, G. Fernlund and F.M. Rossi, J. Biomat. Appl., $2012,27,267-275$.

15. B. J. Jeon, S. Y. Jeong, A. N. Koo, B. C. Kim, Y. S. Hwang and S. C. Lee, Macromol. Res., 2012, 20, 715-724.

16. K. Siggers, H. Frei, G. Fernlund, and F. Rossi, J. Biomed. Mat. Res. Part A, 2010, 94, 877-885.

17. K. Morita, K. Doi, T. Kubo, R. Takeshita, S. Kato and Y. Akagawa, Acta Biomat., $2010,6,2808-2815$.

18. Q. Yuan, T. Kubo, K. Doi, K. Morita, R. Takeshita, S. Kato, T. Shiba and Y. Akagawa, Acta Biomat., 2009, 5, 1716-1724.

19. K. D. Kumble and A. Kornberg, J. Biol. Chem., 1996, 270, 5818-5822. 
20. T. Shiba, D. Nishimura, Y. Kawazoe, Y. Onodera, K. Tsutsumi, R. Nakamura and M. Ohshiro, J. Biol. Chem., 2003, 278, 26788-26792.

21. Y. Kawazoe, T. Shiba, R. Nakamura, A. Mizuno, K. Tsutsumi, T. Uematsu, M. Yamaoka, M. Shindoh and T. Kohgo, J. Dent. Res., 2004, 83, 613-618.

22. Y. Hacchou, T. Uematsu, O. Ueda, Y. Usui, S. Uematsu, M. Takahashi, Y. Kawazoe, T. Shiba, S. Kurihara, M. Yamaoka and K. Furusawa, J. Dent. Res., 2007, 86, 893-897.

23. F. A. Ruiz, C. R. Lea, E. Oldfield and R. Docampo, J. Biol. Chem., 2004, 279, $44250-44257$.

24. J. H. Morrissey, S. H. Choi and S. A. Smith., Blood, 2012, 119, 5972-5979.

25. M. D. Jimenez-Nuñez, D. Moreno-Sanchez, L. Hernandez-Rios, Al. BenítezRondán, A. Ramos-Amaya, B. Rodríguez-Bayona, F. Medina, J. A. Brieva and F. A. Ruiz, Haematologica, 2012, 97, 1264-1271.

26. M. Tammenkoski, K. Koivula, E. Cusanelli, M. Zollo, C. Steegborn, A.A. Baykov and R. Lahti, Biochem., 2008, 47, 9707-9713.

27. L. Wang, C.D. Fraley, J. Faridi, A. Kornberg and R.A. Roth, Proc. Natl. Acad. Sci. U S A, 2003, 100, 11249-11254.

28. S. N. J. Morena and R. Docampo, PLoS Pathog., 2013, 9, e1003230.

29. H. Fleisch and S. Bisaz, Nature, 1962, 195, 911-911.

30. H. Fleish, R. Russel and F. Straumann, Nature, 1966, 212, 901-903.

31. H. Fleisch, Progress in Molecular and Subcellular Biology, Springer- Verlag Press, Heidelberg, 1999, 197-215.

32. S. Omelon, J. Georgiou, Z. J. Henneman, L. M. Wise, B. Sukhu, T. Hunt, C. Wynnyckyj, D. Holmyard, R. Bielecki, and M. D. Grynpas, PLos One, 2009, 4, e5634. 
33. J. R. Van Wazer and D. A. Campanella, J. Am. Chem. Soc., 1950, 72, 655-663.

34. M. Okazaki, Y. Yoshida, S. Yamaguchi, M. Kaneno and J. C. Elliot, Biomaterials, 2001, 22, 2459-2464.

35. G. Revilla-López, J. Casanovas, O. Bertran, P. Turon, J. Puiggalí and C. Alemán, Biointerphases, 2013, 8, 10.

36. T. Takeshita, Y. Matsuura, S. Arakawa and M. Okamoto, Langmuir, 2013, 29, $11975-11981$.

37. K. B. Vasconcellos, S. M. McHugh, K. J. Dapsis, A. R. Petty and A. E. Gerdon, J. Nanopart. Res., 2013, 15, 1942.

38. O. Bertran, L. J. del Valle, G. Revilla-López, G. Chaves, L. Cardus, M. T. Casas, J. Casanovas, P. Turon, J. Puiggalí and C. Alemán, Dalton Trans., 2014, 43, 317327.

39. D. Olton, J. Li, M. E. Wilson, T. Rogers, J. Close, L. Huang, N. P. Kumta and C. Sfeir, Biomaterials, 2007, 28, 1267-1279.

40. R. Gonzalez-McQuire, D. W. Green, K. A. Partridge, R. O. C. Oreffo, S. Mann and S. A. Davis, Adv. Mater., 2007, 19, 2236-2240.

41. L. J. del Valle, O. Bertran, G. Chaves, G. Revilla-López, M. Rivas, M. T. Casas, J. Casanovas, P. Turon, J. Puiggalí and C. Alemán, J. Mater. Chem., 2014, 2, 69536966.

42. M. Brundin, D. Figdor, G. Sundqvist and U. Sjögren, J. Endod., 2013, 39, 211-216.

43. S. S. Kamat and F. M. Raushel, Curr. Opin. Chem. Bio., 2013, 17, 589-596.

44. F. H. Ebetino and R. G. G. Russell, J. Bone Miner Res., 2005, 20, 259.

45. F. H. Ebetino and S. M. Dansereau, Biophosphonate antiresorptive structureactivity relationships, Elsevier Press, Amsterdam, 1995, pp: 139-153.

46. F. H. Ebetino and M. D. Francis, Rev. Contemp. Pharmacother., 1998, 9, 233-243. 
47. R. G. G. Russell and F.H. Ebetino, Osteoporos. Int., 2008, 19, 733-759.

48. N. Gronich and G. Rennet, Nat. Rev. Clin. Oncol., 2013, 10, 625-642.

49. H. Klug and L. Alexander, X-Ray Diffraction Procedure for Polycrystallite and Amorphous Materials, $2^{\text {nd }}$. Edition, John Wiley and Sons Press, New York, 1974.

50. E. Landi, A. Tampieri, G. Celotti and S. Sprio, J. Eur. Ceram. Soc., 2000, 20, $2377-2387$.

51. M. J. Frisch, G. W. Trucks, H. B. Schlegel, G. E. Scuseria, M. A. Robb, J. R. Cheeseman, G. Scalmani, V. Barone, B. Mennucci, G. A. Petersson, H. Nakatsuji, M. Caricato, X. Li, H. P. Hratchian, A. F. Izmaylov, J. Bloino, G. Zheng, J. L. Sonnenberg, M. Hada, M. Ehara, K. Toyota, R. Fukuda, J. Hasegawa, M. Ishida, T. Nakajima, Y. Honda, O. Kitao, H. Nakai, T. Vreven, J. A. Jr Montgomery, J. E. Peralta, F. Ogliaro, M. Bearpark, J. J. Heyd, E. Brothers, K. N. Kudin, V. N. Staroverov, R. Kobayashi, J. Normand, K. Raghavachari, A. Rendell, J. C. Burant, S. S. Iyengar, J. Tomasi, M. Cossi, N. Rega, J. M. Millam, M. Klene, J. E. Knox, J. B. Cross, V. Bakken, C. Adamo, J. Jaramillo, R. Gomperts, R. E. Stratmann, O. Yazyev, A. J. Austin, R. Cammi, C. Pomelli, J. W. Ochterski, R. L. Martin, K. Morokuma, V. G. Zakrzewski, G. A. Voth, P. Salvador, J. J. Dannenberg, S. Dapprich, A. D. Daniels, O. Farkas, J. B. Foresman, J. V. Ortiz, J. Cioslowski and D. J. Fox, Gaussian 09, revision A.01, Gaussian, Inc.: Wallingford, CT, 2009.

52. L. Stork, P. Muller, R. Dronskowski and J. R. Ortlepp, Z. Kristallogr., 2005, 220, 201-205.

53. C. Lee, W. Yang and R. G. Parr, Phys. Rev. B, 1988, 37, 785-789.

54. A. D. Becke, J. Chem. Phys. 1993, 98, 5648-5652.

55. X.-H. Guan, Q. Liu , G.-H. Chen and C. Shang, J. Colloid Interface Sci., 2005, 289, 319-327. 
56. V. Dalmoro, J. H. Z. dos Santos, E. Armelin, C. Alemán and D. Azambuja, Appl. Surf. Sci., 2013, 273,758-768.

57. X. L. Zhu, J. Chen, L. Scheideler, R. Reichl and J. Geis-Gerstoefer, Biomaterials, 2004, 25, 4087-4103.

58. W. Y. P.Y. Shih and T.S. Chin, J. Non-Cryst. Solids, 1999, 244, 211-222.

59. H. Goretzki, H.-U. Chun, M. Sammet, M. and R. Bruckner, J. Non-Cryst. Solids 1980, 42, 49-60.

60. C. S. K. Singamsetty, C. U. Pittman, G. L. Booth, G.-R. He and S. D. Gardner, Carbon, 1995, 33, 587-595.

61. N. Almora-Barrios, K. F. Austen and N. H. de Leeuw, Langmuir, 2009, 25, 50185025 .

62. N. H. de Leeuw, Chem. Commun., 2001, 17, 1646-647.

63. D. Mkhonto and N. H. de Leeuw, J. Mater. Chem., 2002, 12, 2633-2642.

64. J. Kirkham, S. J. Brookes, R. C. Shore, S. R. Wood, D. A. Smith, J. Zhang, H. Chen and C. Robinson, Curr. Opin. Colloid Interface Sci., 2002, 7, 124-132.

65. J. P. Simmer and A. G. Fincham, Crit. Rev. Oral Biol. Med., 1995, 6, 84-108.

66. D. Magne, P. Pilet, P. Weiss and G. Daculsi, Bone, 2001, 29, 547-552.

67. L. Wang, G. H. Nancollas, Chem. Rev. 2008, 108, 4628-4669.

68. K. Onuma, Prog. Cryst. Growth Charact. Mater. 2006, 52, 223-245.

69. O. Bertran, L. J. del Valle, G. Revilla-López, M. Rivas, G. Chaves, M. T. Casas, J. Casanovas, P. Turon, and J. Puiggalí, Chem. Eur. J. 2015, 21, 2537-2546.

70. Y. Liu, W. Wu, G. Sethuraman and G. H. Nancollas, J. Cryst. Growth, 1997, 174, $386-392$

71. M. Murshed, D. Harmey, J. L. Millán, M. D. McKee and G. Karsenty, Genes Dev., 2005, 19, 1093-1104 
Table 1. Characteristic FTIR bands of the species studied in this work.

\begin{tabular}{lll}
\hline Compound & & $v$ \\
\hline ACP and cHAp & $\mathrm{PO}_{4}^{3-} v_{1}$ & 962 \\
& $\mathrm{PO}_{4}^{3-} \quad v_{3}$ & $1022,1059,1089$ \\
polyP & $\mathrm{P}-\mathrm{O}-\mathrm{P}$ symmetric stretching & 734 \\
& $\mathrm{P}-\mathrm{O}-\mathrm{P}$ asymmetric stretching & 890 \\
& $\mathrm{PO}_{3}^{2-}$ vibrations & $1100-1200$ \\
& $\mathrm{P}-\mathrm{O}-\mathrm{P}$ symmetric stretching & 736 \\
$\mathrm{P}_{2} \mathrm{O}_{7}^{4-}$ & $\mathrm{P}-\mathrm{O}-\mathrm{P}$ asymmetric stretching & 889 \\
& $\mathrm{PO}_{3}^{2-}$ vibrations & $1100-1200$ \\
& $\mathrm{P}-\mathrm{O}-\mathrm{CH}{ }_{2}$ stretching & 1070 \\
& asymmetric vibrations of alkylphosphonic & 939 \\
& symmetric vibrations of alkylphosphonic & 1000 \\
& $\mathrm{P}-\mathrm{C}$ stretching & 985 \\
\hline
\end{tabular}


Table 2. Molecular formula of all systems studied in this work

\begin{tabular}{lll}
\hline$\#$ & System & Molecular formula \\
\hline Adsorbed compounds & Orthophosphate & $\mathrm{PO}_{4}^{3-}$ \\
& Pyrophosphate & $\mathrm{P}_{2} \mathrm{O}_{7}^{4-}$ \\
& PolyP & $\mathrm{P}_{3} \mathrm{O}_{10}^{5-}$ \\
& ATMP & $\mathrm{N}_{\left(\mathrm{CH}_{2} \mathrm{PO}_{3}\right)_{3}^{6-}}$ \\
& $1 \times 1 \times 1$ slab model & $\mathrm{Ca}_{10}\left(\mathrm{PO}_{4}\right)_{6}(\mathrm{OH})_{2}$ \\
& $1 \times 1 \times 2$ slab model & $\mathrm{Ca}_{20}\left(\mathrm{PO}_{4}\right)_{12}(\mathrm{OH})_{4}$ \\
& $2 \times 1 \times 2$ slab model & $\mathrm{Ca}_{40}\left(\mathrm{PO}_{4}\right)_{24}(\mathrm{OH})_{8}$ \\
& $1 \times 2 \times 2$ slab model & $\mathrm{Ca}_{40}\left(\mathrm{PO}_{4}\right)_{24}(\mathrm{OH})_{8}$ \\
& $2 \times 1 \times 1$ slab model & $\mathrm{Ca}_{20}\left(\mathrm{PO}_{4}\right)_{12}(\mathrm{OH})_{4}$ \\
& $2 \times 2 \times 1$ slab model & $\mathrm{Ca}_{40}\left(\mathrm{PO}_{4}\right)_{24}(\mathrm{OH})_{8}$ \\
& $2 \times 2 \times 2$ slab model & $\mathrm{Ca}_{80}\left(\mathrm{PO}_{4}\right)_{48}(\mathrm{OH})_{16}$ \\
$3 \times 3 \times 1$ slab model & $\mathrm{Ca}_{90}\left(\mathrm{PO}_{4}\right)_{54}(\mathrm{OH})_{18}$ \\
\hline
\end{tabular}


Table 3. Physical parameters as determined by SEM and X-ray diffraction for ACP and cHAp.

\begin{tabular}{ccc}
\hline & ACP & cHAp \\
\hline Average radius $(R)$ and length $(\ell)$ of the & $R=2.6 \pm 0.2 \mathrm{~nm}$ & $R=2.8 \pm 0.2 \mathrm{~nm}$ \\
observed nanostructures & & $\ell=21 \pm 3 \mathrm{~nm}$ \\
Cristallinity (see Eqn 1) & $\chi_{c}=3 \pm 1 \%$ & $\chi_{c}=56 \pm 4 \%$ \\
Crystallite size (see Eqn 2) & $L=6 \pm 1 \mathrm{~nm}$ & $L=55 \pm 8 \mathrm{~nm}$ \\
\hline
\end{tabular}


Table 4.

\begin{tabular}{|c|c|c|c|}
\hline Surface & Slab model & Adsorbate & BE (kcal/mol) \\
\hline \multirow[t]{6}{*}{$(001)$} & $2 \times 2 \times 1$ & $\mathrm{PO}_{4}^{3-}$ & -518.8 \\
\hline & $2 \times 2 \times 2$ & $\mathrm{PO}_{4}^{3-}$ & -526.4 \\
\hline & $3 \times 3 \times 1$ & $\mathrm{PO}_{4}^{3-}$ & -548.1 \\
\hline & & $\mathrm{P}_{2} \mathrm{O}_{7}^{4-}$ & Unstable \\
\hline & & PolyP & -735.0 \\
\hline & & ATMP & -1138.5 \\
\hline \multirow[t]{6}{*}{ (100) } & $1 \times 1 \times 2$ & $\mathrm{PO}_{4}^{3-}$ & -531.5 \\
\hline & $2 \times 1 \times 2$ & $\mathrm{PO}_{4}^{3-}$ & -545.9 \\
\hline & $1 \times 2 \times 2$ & $\mathrm{PO}_{4}^{3-}$ & -594.9 \\
\hline & & $\mathrm{P}_{2} \mathrm{O}_{7}^{4-}$ & -748.8 \\
\hline & & PolyP & -871.5 \\
\hline & & ATMP & Unstable \\
\hline
\end{tabular}




\section{CAPTIONS TO FIGURES}

Figure 1. FTIR spectra of cHAp (left) and ACP (right) samples incubated in presence of different concentrations of polyP $\left(25,50,100\right.$ and $200 \mathrm{mM}$; top), $\mathrm{P}_{2} \mathrm{O}_{7}^{4-}$ (12.5, 25, 50 and $100 \mathrm{mM}$; middle) and $\operatorname{ATMP}(25,50,100$ and $200 \mathrm{mM}$; bottom). The concentration of adsorbate increases from top-to-down. The most important band are marked with arrows.

Figure 2. FTIR spectra of cHAp (left) and ACP (right) samples incubated in presence of polyP (200 mM; top), $\mathrm{P}_{2} \mathrm{O}_{7}^{4-}(100 \mathrm{mM}$; middle) and ATMP (200 mM; bottom) at $\mathrm{pH} 6,7$ and 9. The $\mathrm{pH}$ increases from top-to-down. The most important band are marked with arrows.

Figure 3. Unit cell (left) and $n \times m \times n$ slab models (right) used to represent the (a) (001) and (b) (100) surfaces in DFT calculations.

Figure 4. Lowest energy structure obtained for the adsorption of $\mathrm{PO}_{4}^{3-}$ onto the (a) (001) and (b) (100) surfaces of HAp. The (001) and (100) surfaces are represented by $3 \times 3 \times 1$ and $1 \times 2 \times 2$ slab models. $\mathrm{Ca}^{2+} \ldots \mathrm{O}$ interactions are indicated by blue lines, distances (in $\AA$ ) between the coordination sites and the oxygen atoms of the adsorbate being also displayed.

Figure 5. (a) Lowest energy structure and (b) representative local minimum obtained for the adsorption of $\mathrm{P}_{2} \mathrm{O}_{7}^{4-}$ onto the (100) surface of HAp. The (100) surface is represented by a $1 \times 2 \times 2$ slab model. $\mathrm{Ca}^{2+} \ldots \mathrm{O}$ interactions are indicated by blue lines, distances (in $\AA$ ) between the coordination sites and the oxygen atoms of the adsorbate being also displayed. 
Figure 6. Lowest energy structure obtained for the adsorption of polyP onto the (a) (001) and (b) (100) surfaces of HAp. The (001) and (100) surfaces are represented by $3 \times 3 \times 1$ and $1 \times 2 \times 2$ slab models. $\mathrm{Ca}^{2+} \ldots \mathrm{O}$ interactions are indicated by blue lines, distances (in $\AA$ ) between the coordination sites and the oxygen atoms of the adsorbate being also displayed.

Figure 7 Lowest energy structure obtained for the adsorption of ATMP onto the (001) surface of HAp, which is represented by a $3 \times 3 \times 1$ slab model. $\mathrm{Ca}^{2+} \ldots \mathrm{O}$ interactions are indicated by blue lines, distances (in $\AA$ ) between the coordination sites and the oxygen atoms of the adsorbate being also displayed. 

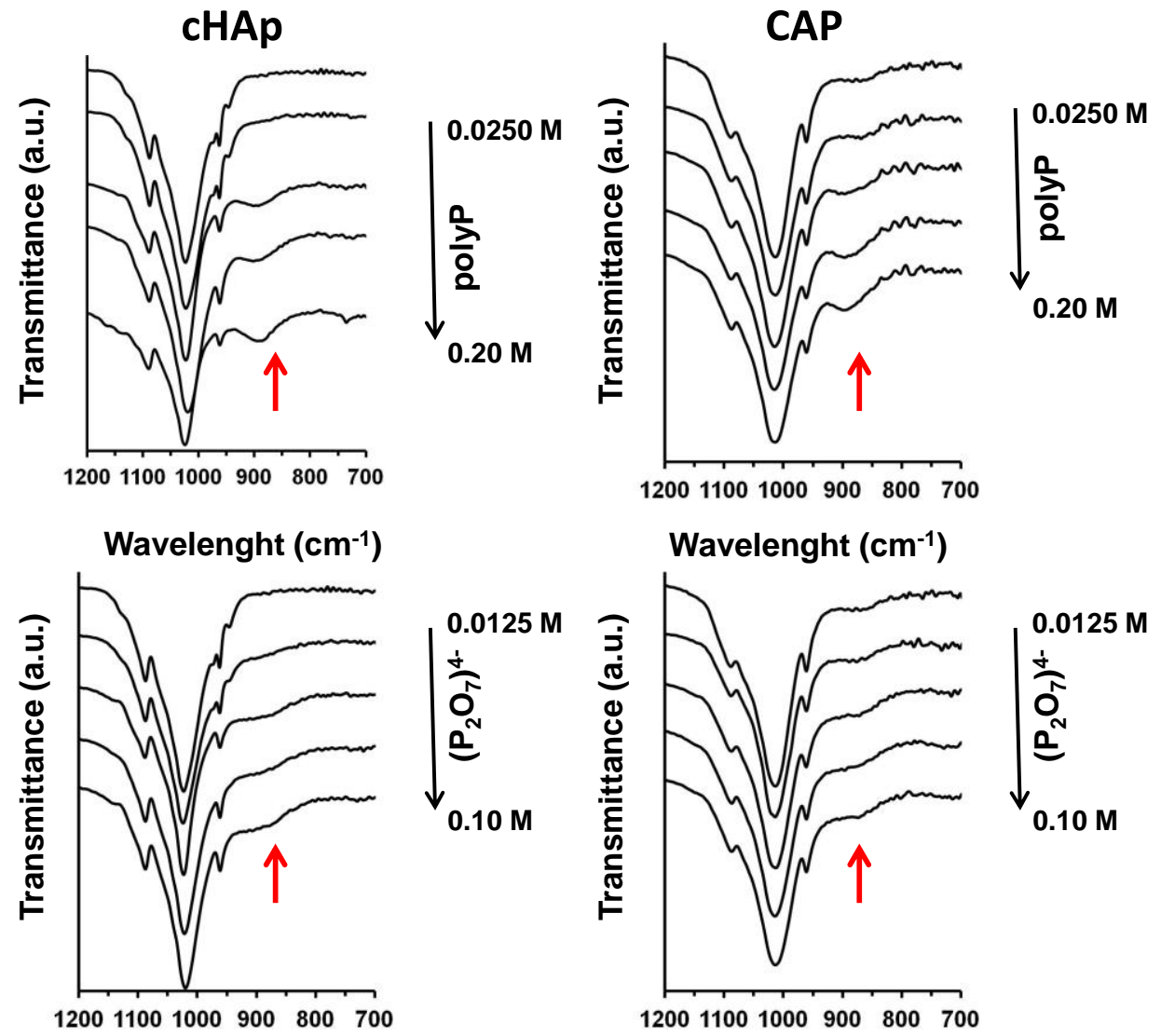

Wavelenght $\left(\mathrm{cm}^{-1}\right)$

Wavelenght $\left(\mathrm{cm}^{-1}\right)$
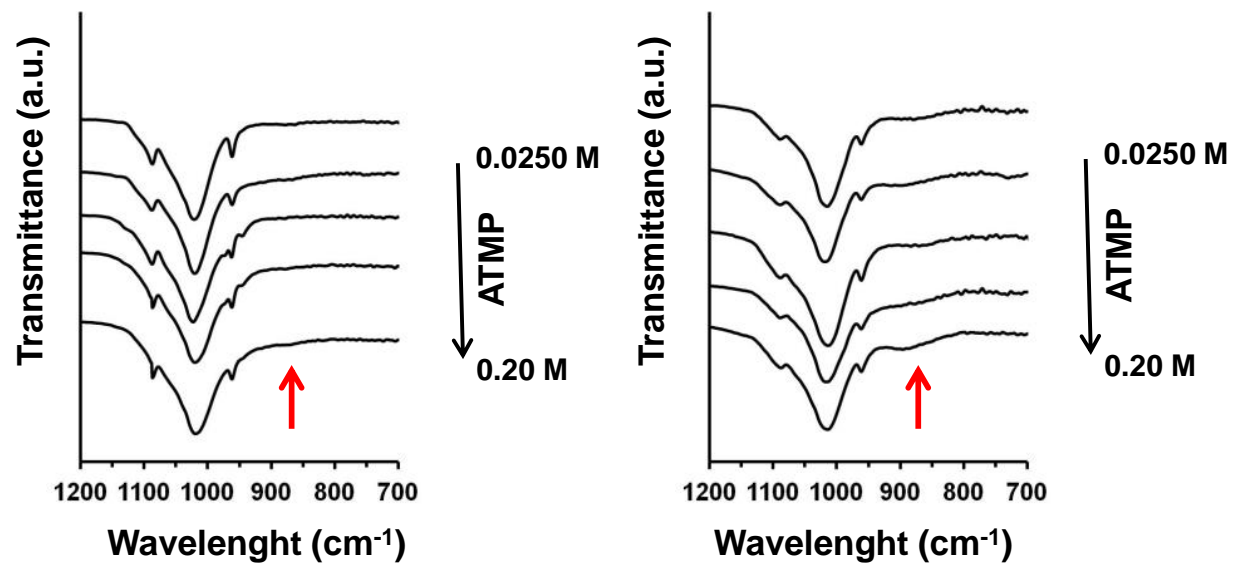

Figure 1 

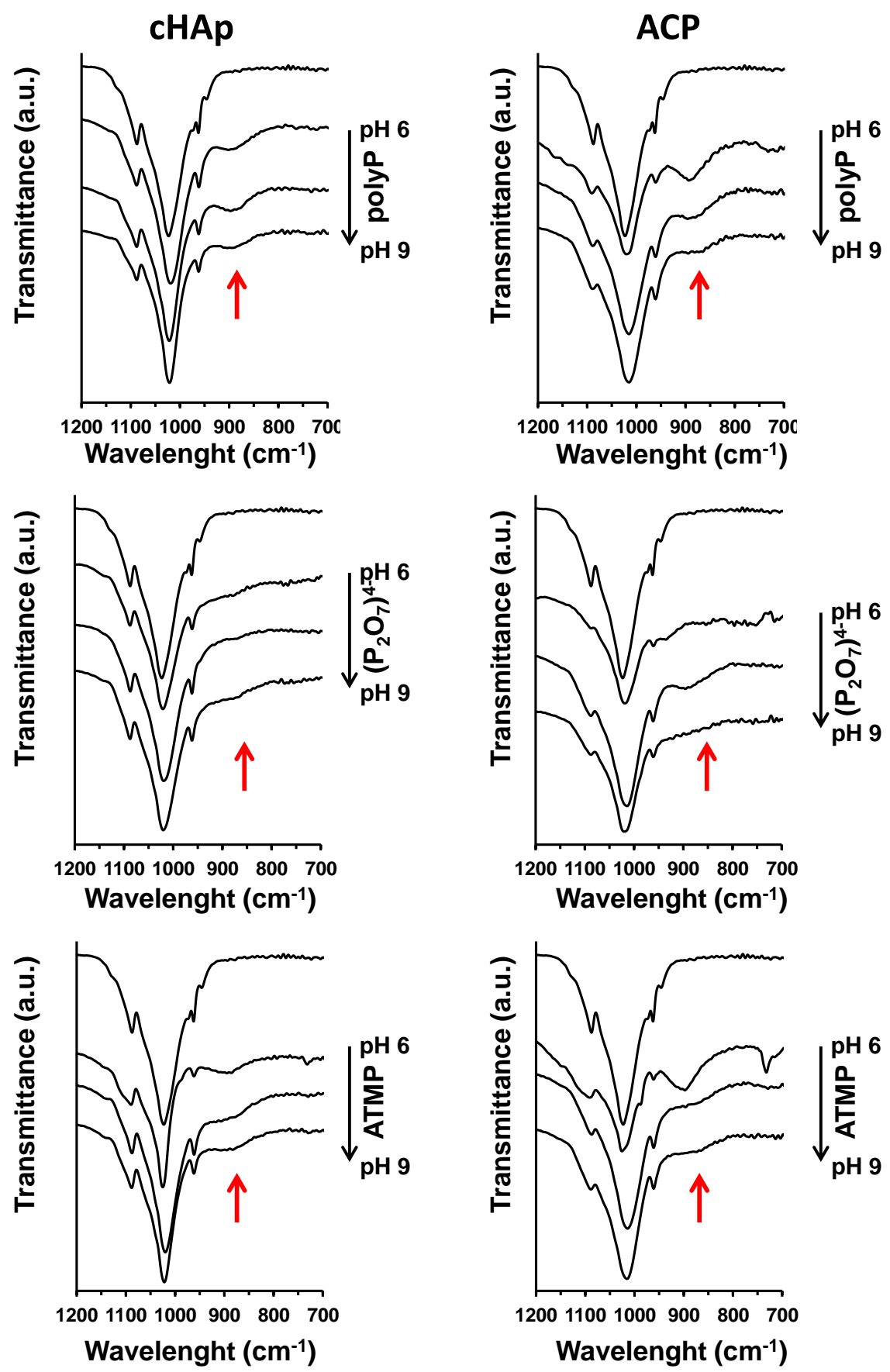

Figure 2 

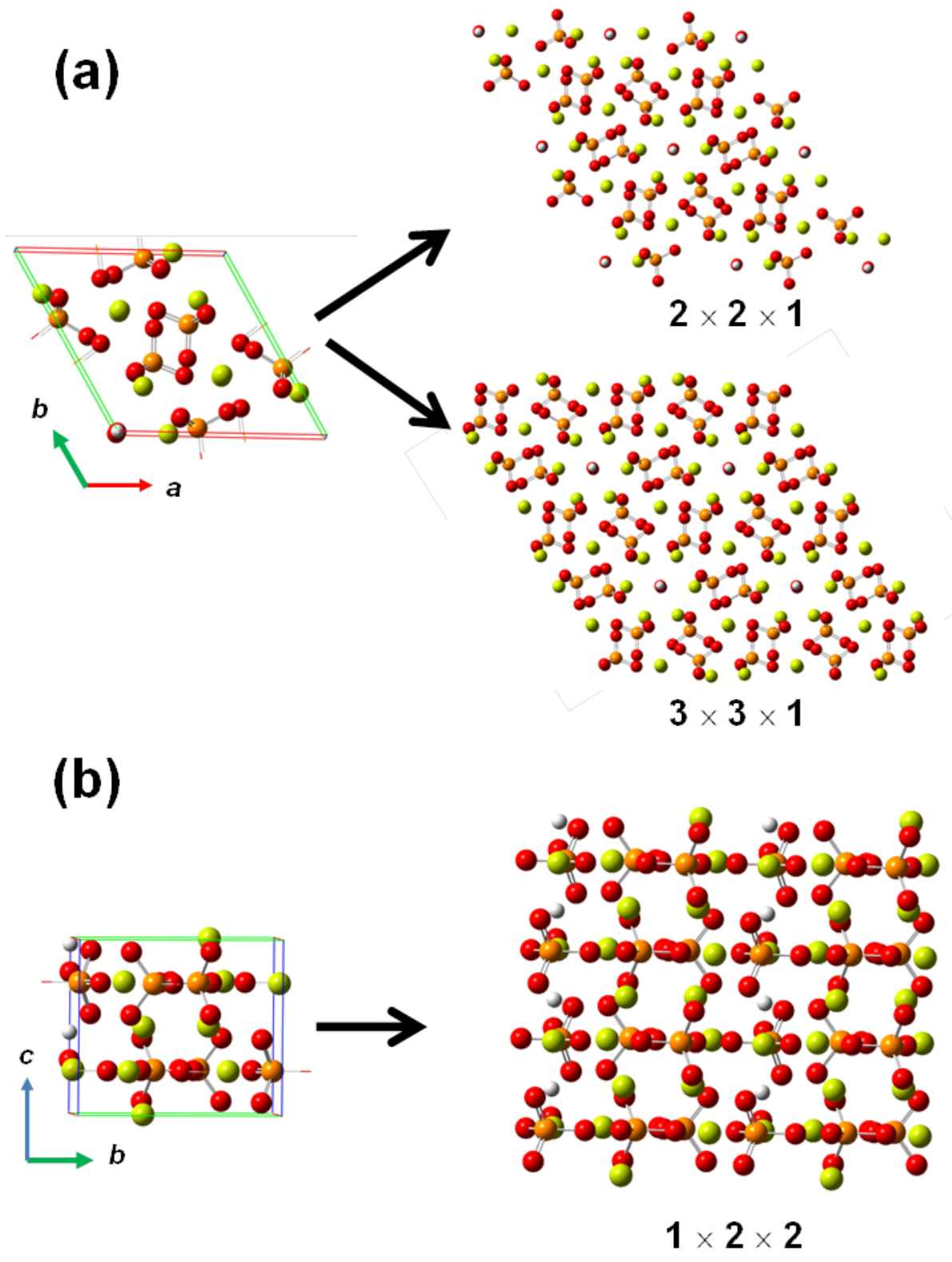

Figure 3 


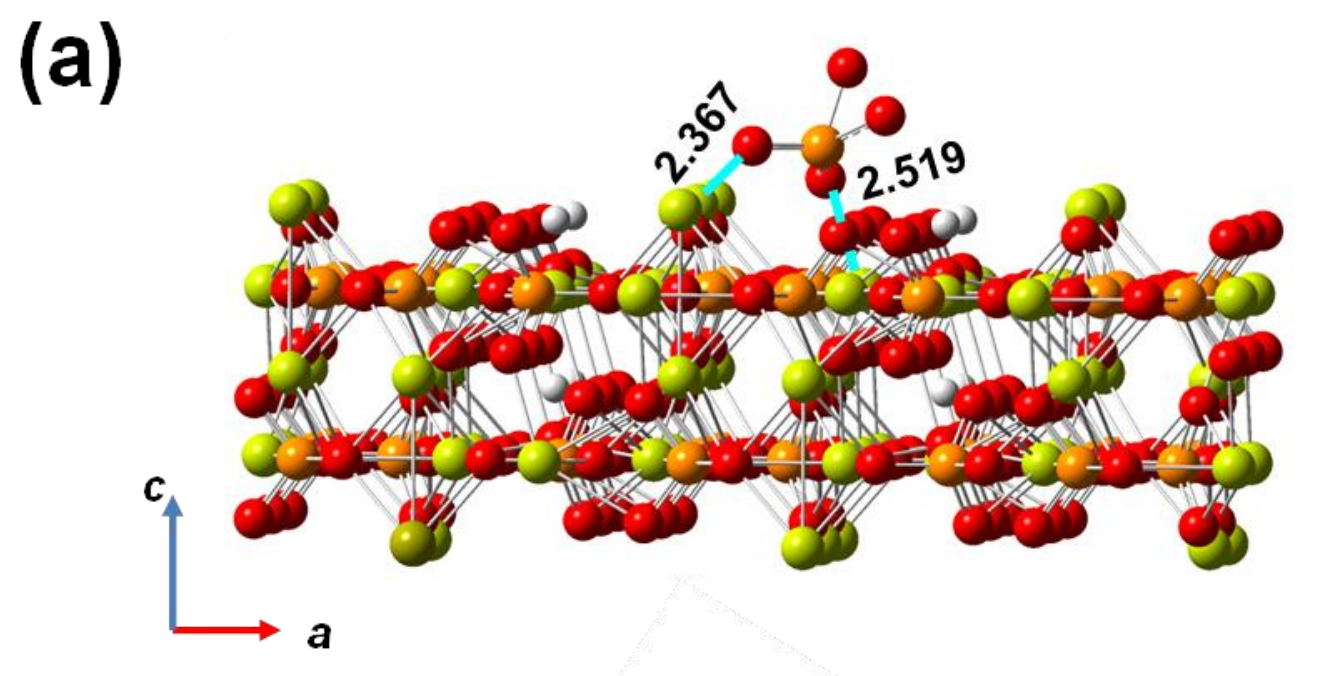

(b)

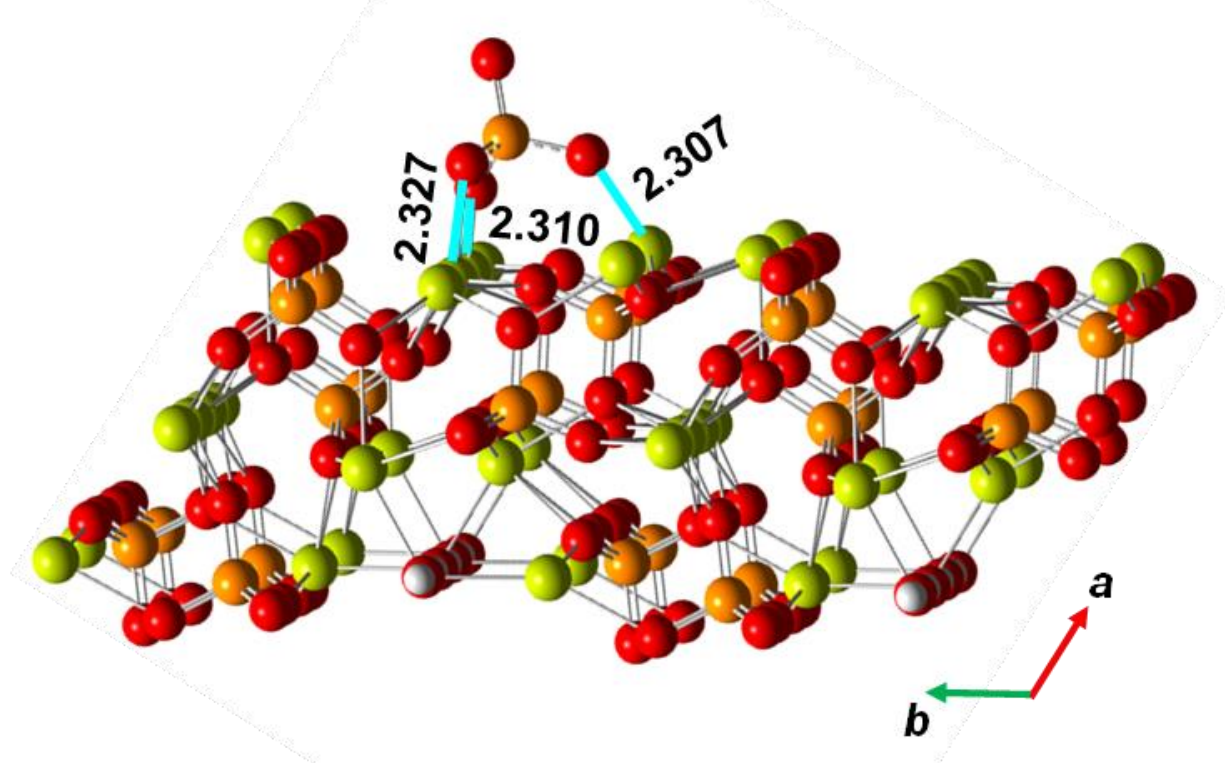

Figure 4 
(a)

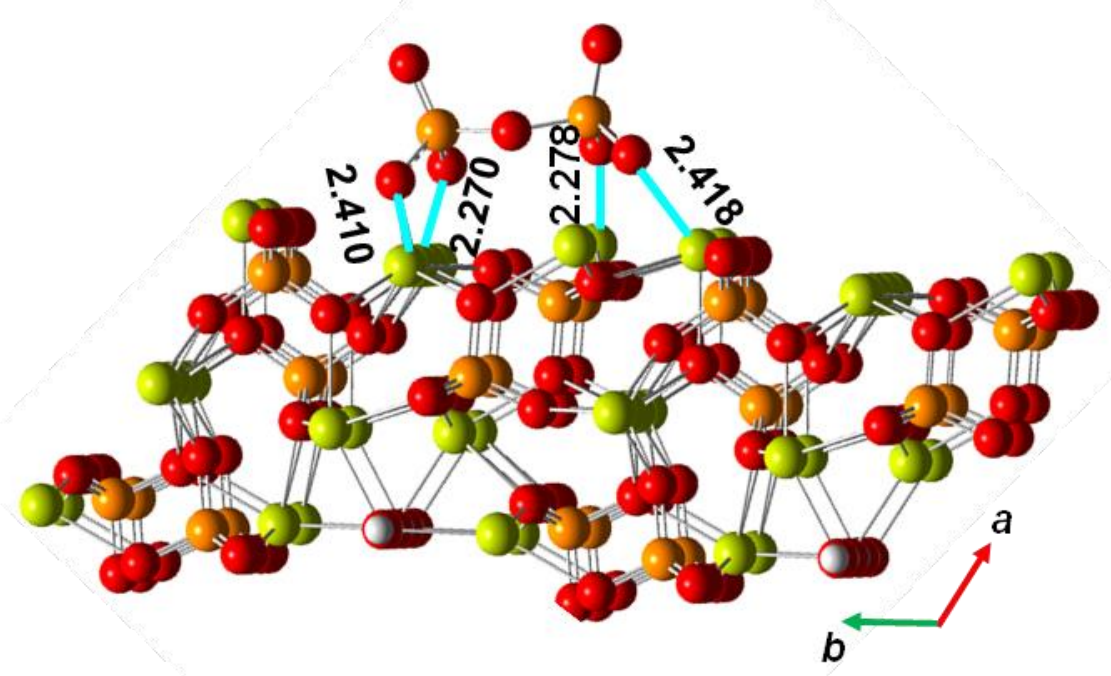

(b)

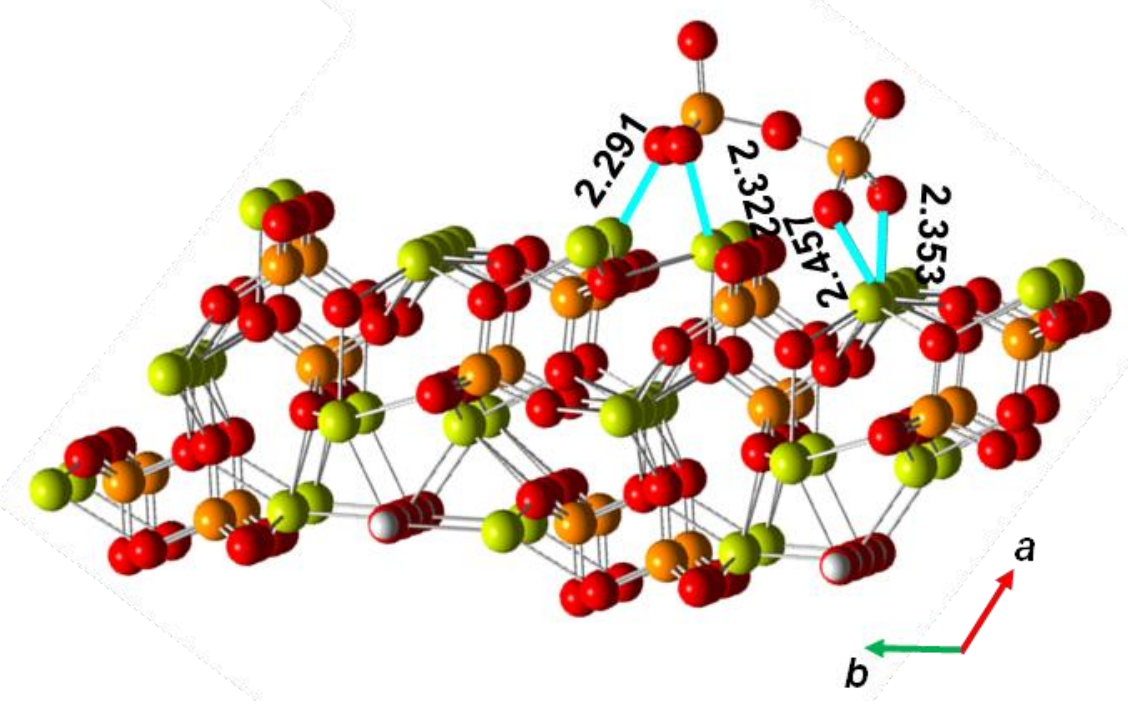

Figure 5 
(a)
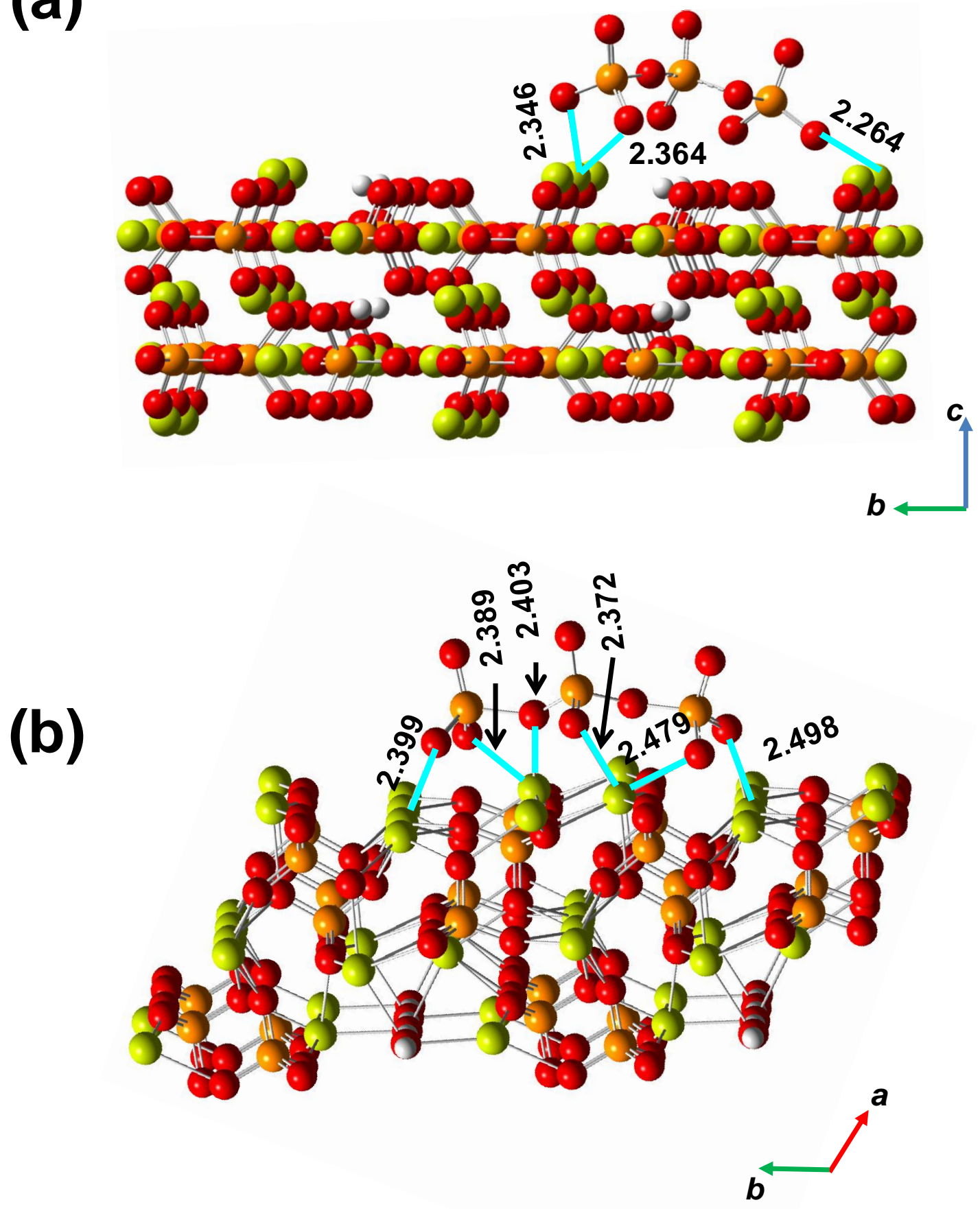

Figure 6 


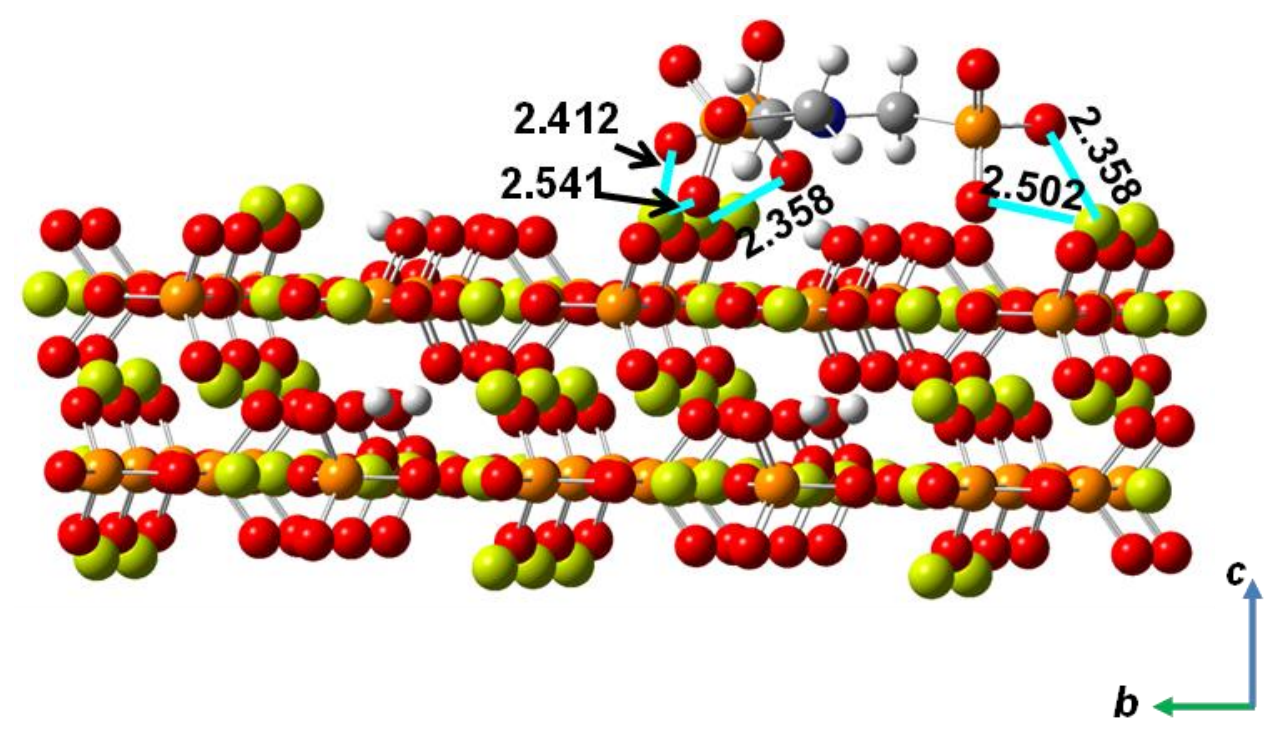

Figure 7 


\section{Graphical Abstract}

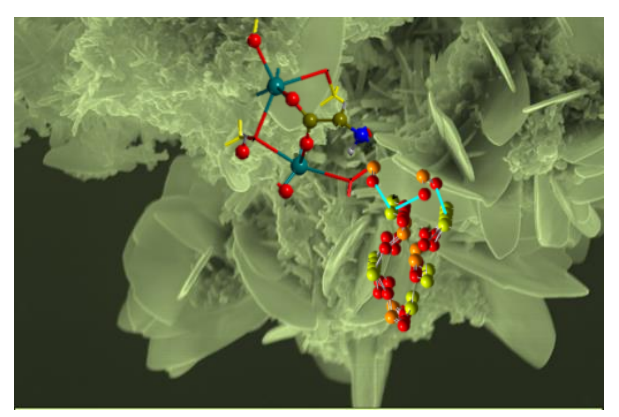

The adsorption of different phosphates and a triphosphonate onto hydroxyapatite has been highlighted combining experiments and theoretical calculations. 